\title{
Is High Grade Prostatic Intraepithelial Neoplasia a Risk Factor for Prostate Cancer?-A Local Study
}

\author{
Alaa Al-Deen Al-Dabbagh1, Ehab Jasim Mohammad², Waleed Nassar Jaffal ${ }^{3}$ \\ ${ }^{1}$ Department of Surgery, College of Medicine, Al-Mustansiriyah University, Baghdad, Iraq \\ ${ }^{2}$ College of Medicine, IbnSina University of Medical \& Pharmaceutical Sciences, Baghdad, Iraq \\ ${ }^{3}$ Department of Surgery, College of Medicine, Al-Anbar University, Al-Anbar, Iraq \\ Email: alaaa1962@yahoo.co.uk,ehabgmh@yahoo.com, Waleed_aljaffal@yahoo.com
}

How to cite this paper: Al-Dabbagh, A.A.-D., Mohammad, E.J. and Jaffal, W.N. (2018) Is High Grade Prostatic Intraepithelial Neoplasia a Risk Factor for Prostate Cancer?-A Local Study. Open Journal of Urology, 8, 1-7.

https://doi.org/10.4236/oju.2018.81001

Received: December 18, 2017

Accepted: January 13, 2018

Published: January 16, 2018

Copyright $\odot 2018$ by authors and Scientific Research Publishing Inc. This work is licensed under the Creative Commons Attribution International License (CC BY 4.0).

http://creativecommons.org/licenses/by/4.0/

\begin{abstract}
Objective: To determine the consequence of recognizing high grade prostatic intraepithelial neoplasia (HGPIN) \& its extent on initial sextant prostatic biopsy then identifying its associated risk of finding prostate cancer on subsequent biopsy. Patients and methods: Seventy-one men were subjected to transrectal ultrasound guided sextant prostate biopsy due to elevated serum prostate specific antigen (S.PSA) $>4 \mathrm{ng} / \mathrm{ml}$, an abnormal digital rectal examination (DRE) and/or transrectal ultrasound (TRUS) findings. The number, percentage, as well as bilateral and multifocal involvement of specimens positive for HGPIN were recorded in every patient. The percentage of cancer detected in these patients on repeat biopsy within 1 year of the initial biopsy was also recorded. Results: The mean age and mean S.PSA level of our patients was 59.9 years and $7.9 \mathrm{ng} / \mathrm{ml}$ respectively. Of the 71 patients studied, initial biopsy revealed that $(32.4 \%)$ had benign prostatic hyperplasia (BPH), (36.62\%) had carcinoma, (25.35\%) had HGPIN and (5.63\%) had chronic prostatitis. On repeat biopsy within 1 year of initial biopsy cancer of the prostate was detected in $33.3 \%$ of our patients who were diagnosed with HGPIN on $1^{\text {st }}$ biopsy. All of them had multifocal involvement on the initial biopsy. Conclusion: Recognizing HGPIN on $1^{\text {st }}$ biopsy (particularly multifocal involvement) is associated with great risk of prostate cancer development on subsequent biopsy, thus comprehensive follow-up of these patients is necessary.
\end{abstract}

\section{Keywords}

HGPIN, Prostate Cancer, Biopsy

\section{Introduction}

In urinary tract histopathology, HGPIN is considered prostatic gland anomaly 
and thought to antecede the development of adenocarcinoma of the prostate [1] [2].

Prostatic intraepithelial neoplasia (PIN) was previously classified into various aspects, depending on the level of atypical cell. It was categorized as PIN1, 2 or 3, in order of increasing irregularities of the cell. For the time being, PIN1 indicates low grade PIN, PIN2 and PIN3 are gathered together as HGPIN [3]. Only HGPIN appeared to be a risk factor for prostate adenocarcinoma. Because LGPIN is not important and does not need repeat biopsy or therapy, it is not recorded in the histopathology reports. Thus, PIN has become synonymous to HGPIN [4].

On a subsidiary biopsy, given a diagnosis of a HGPIN, the incidence of identifying prostatic cancer is approximately $30 \%$ [5].

HGPIN is presently known to be the most probably precursor of invasive adenocarcinoma of the prostate for epidemiological, morphological, genetic, clinical and spatial causes [6]. HGPIN raises the hazard 15-times higher in comparison to those without HGPIN and provides the greatest risk proportion in developing cancer of the prostate [7].

The incidence, range \& degree of HGPIN seem to increase with the age of the patient [8] [9] \& its prevalence is the same in white \& black races [10].

Patients viewed by urologists practically have PIN in $4.4 \%$ - $25 \%$ of recent needle biopsies. Those subjected to transurethral resection (TUR) have the highest probability of PIN ranging from $2.8 \%$ to $33 \%$ [11] [12].

HGPIN \& prostate cancer have the same morphometric and phenotypic properties. HGPIN occurs mostly in the peripheral zone \& is seen in sites that are continuous with prostate cancer [13] [14]. A rise in the rate of aneuploidy and angiogenesis as the grade of PIN progresses are further proof that HGPIN is an important predictive factor for prostate cancer [15] [16]. HGPIN and prostate cancer participate in the same genetic alterations [17] [18].

The presence of HGPIN warns both the patient and the clinician that it may progress to clinically significant prostatic tumor.

Biopsy remains the ultimate procedure for discovering HGPIN \& early invasive cancer, however noninvasive methods including blood analyses, are being estimated. Serum PSA levels are perhaps increased in patients with HGPIN [19].

The aim of this study is to highlight the significance of recognizing HGPIN on initial prostatic biopsy and to evaluate the relationship between HGPIN and the future development of prostate cancer on subsequent biopsies.

\section{Patients and Methods}

This study was carried out at the urology department of Al-Yarmouk Teaching Hospital in the period between January 2014 and January 2017, it included 71 men with an age ranged from 50 to 80 years complaining of bladder outlet obstructive symptoms (BOO). Patients were evaluated by full history taking $\&$ thorough physical examination including digital rectal examination (DRE) \& investigations by doing urinalysis, urine culture \& sensitivity, blood sugar, $\mathrm{CBC}$, blood 
urea, serum creatinine \& serum prostate specific antigen (PSA). Abdominal \& pelvic ultrasound \& Transrectal ultrasound (TRUS) were performed on all patients. Inclusion criteria included men $(\mathrm{n}=71)$ with elevated S.PSA level $>4 \mathrm{ng} / \mathrm{ml}$, an abnormal DRE and/or TRUS findings. No patients had a prior diagnosis of prostate tumor, or had received radiotherapy, chemotherapy or androgen deprivation therapy.

In every patient we calculated the volume of the prostate using the TRUS then we calculated the PSA density by dividing the total S.PSA by the prostatic volume.

Prostatic biopsies were taken from all patients under transrectal U/S guidance $\&$ antibiotics cover. They were obtained in a systematic sextant biopsy technique with the patient in left decubitus position using an automatic biopsy gun with an 18-gauge needle. Further biopsies were also pointed to the suspicious areas. Each biopsy specimen was coded according to its site (apex, mid, base) and side (right or left) and collected in an isolated container. All biopsy specimens were examined by one pathologist.

The diagnosis of HGPIN in our pathology database was established when it was identified in at least one of the six prostatic biopsies obtained, also the bilateral \& multifocal involvement (the presence of HGPINP in 2 or more biopsy specimens) were recorded in every case.

Men diagnosed with HGPIN underwent repeat second sextant biopsies of the prostate within 1 year of the $1^{\text {st }}$ biopsy.

\section{Results}

A total of 71 patients were included in the study, their mean age was $59.9 \mathrm{y}$. (range 50 - 80). The mean S.PSA level was $7.9 \mathrm{ng} / \mathrm{ml}$ (range 4.9 - 43.31) Table 1.

Prostatic biopsies were obtained due to elevated S. PSA in 52 patients, abnormal DRE in 8 patients and abnormal TRUS in 11 men Table 2.

Table 1. The patients' characteristics.

\begin{tabular}{cc}
\hline Patient's characteristic & Mean (SD) \\
\hline Age, years & $59.9(0.232)$ \\
S.PSA, ng/ml & $7.9(0.300)$ \\
Prostatic volume, ml & $49.1(0.364)$ \\
PSA density & $0.16(0.008)$ \\
\hline
\end{tabular}

Table 2. Indications of prostatic biopsy in our patients.

\begin{tabular}{cc}
\hline Indication & No. of patients (\%) \\
\hline Elevated S.PSA & $52(73.23)$ \\
Abnormal DRE & $8(11.27)$ \\
Abnormal TRUS & $11(15.5)$ \\
Total & $71(100)$ \\
\hline
\end{tabular}


Of the 71 patients studied, initial biopsies revealed 23 men (32.4\%) had benign prostatic hyperplasia, 26 patients $(36.62 \%)$ had cancer, 18 patients $(25.35 \%)$ had HGPIN \& 4 patients (5.63) had chronic prostatitis (Figure 1)

HGPIN was present bilaterally in five of the 18 patients $(27.7 \%)$ while multifocal involvement was present in 7 cases (38.8\%) as shown in Figure 2.

On the repeat biopsy obtained after 12 months of the initial biopsy, cancer of the prostate was detected in $6(33.3 \%)$ out of 18 patients diagnosed with HGPIN. All of those [6] patients had multifocal HGPIN on the initial biopsy.

\section{Discussion}

In our study the mean age was 59.9 years while the median S.PSA level was 7.9 $\mathrm{ng} / \mathrm{ml}$. These values were comparable to those recorded in studies made by Geoman et al. [7], Schoenfield et al. [20] and Arzoz Fabregas et al. [21].

In the current study initial prostatic biopsy was done because of elevated S.PSA in $73.23 \%$, suspicious DRE in $11.27 \%$ and an abnormal TRUS finding in

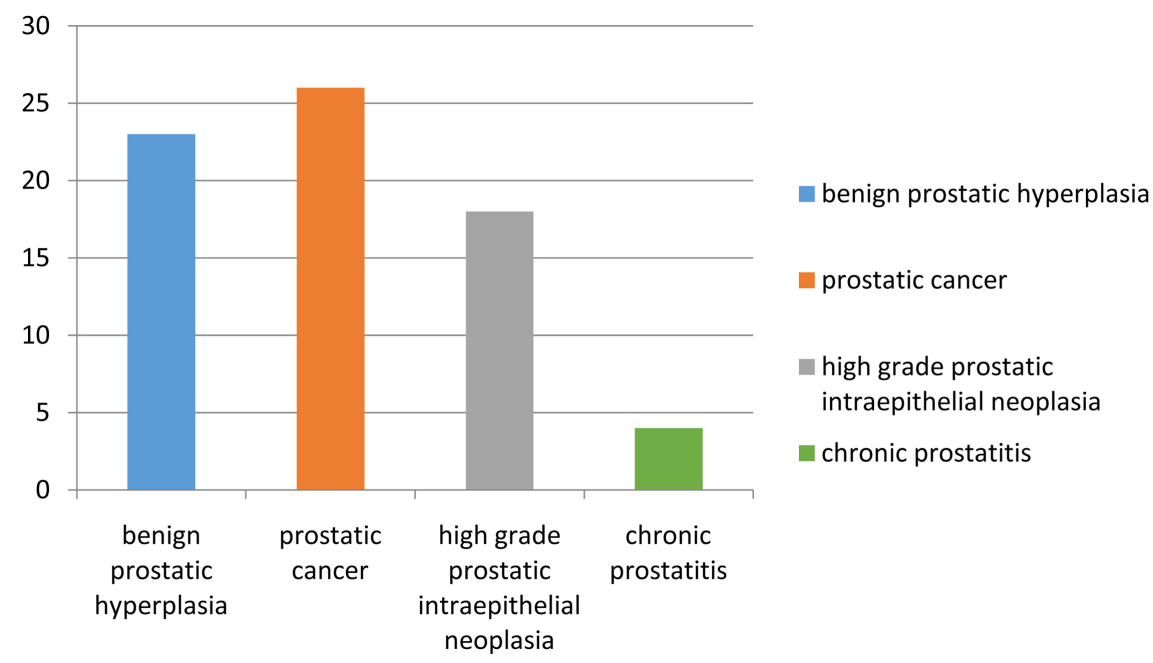

Figure 1. Initial prostatic biopsy findings.

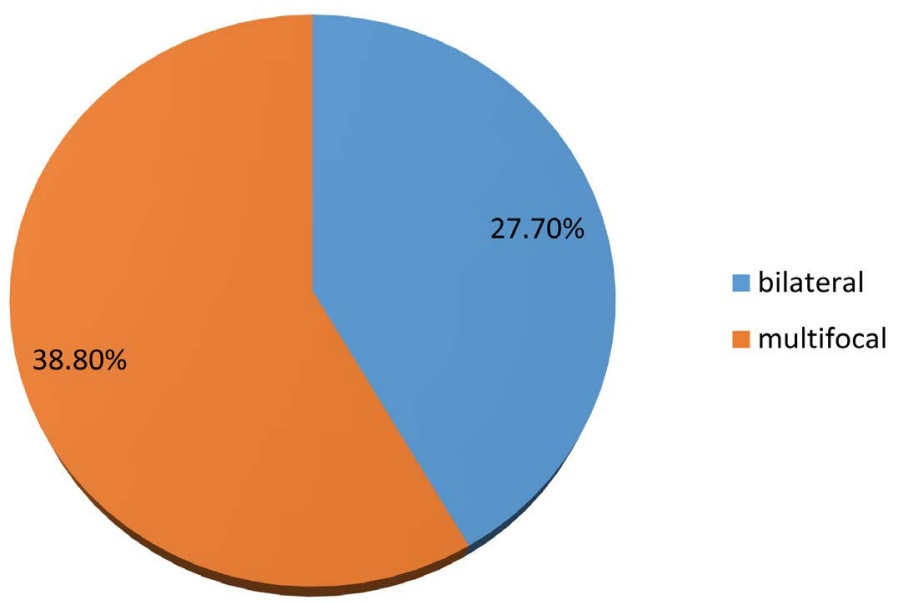

Figure 2. Bilateral \& multifocal involvement of HGPIN. 
15.5\%. These results agreed with that of Geoman et al. [7].

In the present study the incidence of HGPIN on the initial biopsy was (25.35\%). This was in accordance with Schoenfield et al. (22\%) [20], De Nunzio et al. (22\%) [22] and Bostwick (4.4\% - 25\%) [2], but it was in disagreement with other studies (Goeman et al. (11.2\%) [7], Abdel-kalek et al. (2.7\%) [23], Bostwick et al. (9\%) [24] and Borboroglu et al. (9.8\%) [25]).

Prostatic cancer was identified on repeat biopsy in $33.3 \%)$ of our patients with HGPIN on the $1^{\text {st }}$ biopsy; all of them were with multifocal involvement on the initial biopsy. This finding was in consistence with Kronz et al. [26] and Schoenfield et al. [20] who found cancer of the prostate on the $2^{\text {nd }}$ biopsy in third of their patients having HGPIN on the $1^{\text {st }}$ biopsy with higher rate of cancer detection in multifocal than unifocal HGPIN. This indicates that the prostate cancer risk is increased with the increase in the number of specimens found to have HGPIN on the $1^{\text {st }}$ biopsy. Our result also agreed with that of Bostwick et al. [2], Abdel-khalek et al. [23] and Rosser et al. [27], However, it disagreed with studies that revealed lower prostate detection rate (De Nunzio et al. [22], Kamoi et al. [28] and Epstein \& Herawi [29]) and other studies with higher prostate detection rate (Keetch et al. [30] and Borboroglu et al. [25]).

\section{Conclusion}

Patients recognized with HGPIN are at great risk of developing cancer of the prostate on subsequent prostate biopsy particularly those diagnosed with multifocal HGPIN on initial biopsy so close follow-up of these patients is recommended.

\section{References}

[1] Montironi, R., Muzzucchelli, R., Lopez-Beltran, A., et al. (2007) Mechanisms of Disease: High Grade Prostatic Intraepithelial Neoplasia and Other Proposed Preneoplastic Lesions in the Prostate. Nature Clinical Practice Urology, 4, 321-332. https://doi.org/10.1038/ncpuro0815

[2] Bostwick, D.G. and Qian, J. (2004) High Grade Prostatic Intraepithelial Neoplasia. Modern Pathology, 17, 360-379. https://doi.org/10.1038/modpathol.3800053

[3] Montironi, R., Mazzucchelli, R., Algaba, F. and Lopez-Beltran, A. (2000) Morphological Identification of the Patterns of Prostatic Intraepithelial Neoplasia and Their Importance. Journal of Clinical Pathology, 53, 655-665. https://doi.org/10.1136/jcp.53.9.655

[4] Wikipedia (2017) High Grade Prostatic Intraepithelial Neoplasia. Wikipedia, The Free Encyclopedia

[5] Leite, K.R., Camara-Lopes, L.H., Cury, J., et al. (2008) Prostate Cancer Detection at Rebiopsy after an Initial Benign Diagnosis: Results Using Sextant Extended Prostate Biopsy. CLINICS, 63, 339-342. https://doi.org/10.1590/S1807-59322008000300009

[6] Vis, A.N. and Van der Kwast, T.H. (2001) Prostatic Intraepithelial Neoplasia and Putative Precursor Lesions of Prostate Cancer Clinical Perspective. BJU International, 88, 147-157. https://doi.org/10.1046/j.1464-410x.2001.02295.x

[7] Geoman, L., Joniau, S., Ponette, D., et al. (2003) Is Low Grade Prostatic Intraepi- 
thelial Neoplasia a Risk Factor for Cancer? Prostate Cancer and Prostatic Diseases, 6, 305-310. https://doi.org/10.1038/sj.pcan.4500681

[8] Gian, J., Wollan, P. and Bostwick, D.G. (1997) The Extent and Multi-Centricity of High Grade Prostatic Intraepithelial Neoplasia Clinically Localized Prostatic Adenocarcinoma. Human Pathology, 28, 143-148. https://doi.org/10.1016/S0046-8177(97)90097-6

[9] Sakr, W.A., Hass, G.P., Cassin, B.F., et al. (1993) The Frequency of Carcinoma and Intraepithelial Neoplasia of the Prostate in Young Male Patients. Journal of Urology, 150, 379-385. https://doi.org/10.1016/S0022-5347(17)35487-3

[10] Sakr, W.A., Sarkar, F.H., Snepathi, P., et al. (1993) Measurement of Cellular Proliferation in Human Prostate by AgNOR, PCNA and SPF. Prostate, 22, 147-154. https://doi.org/10.1002/pros.2990220207

[11] Gaudin, P.B., Sesterhenn, I.A., Wojno, K.J., et al. (1997) Incidence and Clinical Significance of High Grade Prostatic Intraepithelial Neoplasia in TURP Specimens. Urology, 49, 558-563. https://doi.org/10.1016/S0090-4295(96)00542-0

[12] Brawer, M.K., Bigler, S.A., Sohlberg, O.E., et al. (1991) Significance of Prostatic Intraepithelial Neoplasia on Prostate Needle Biopsy. Urology, 38, 103-107. https://doi.org/10.1016/S0090-4295(05)80067-6

[13] Bostwick, D.G., Montironi, R., Sesterhenn, I.A., et al. (2000) Diagnosis of Prostatic Intraepithelial Neoplasia: Prostate Working Group/Consensus Report. Scandinavian Journal of Urology and Nephrology, 205, 3-10. https://doi.org/10.1080/003655900750169266

[14] Montironi, R., Scarpelli, M., Sisti, S., et al. (1990) Quantitative Analysis of Prostatic Intraepithelial Neoplasia on Tissue Section. Analytical and Quantitative Cytology and Histology, 12, 366-372.

[15] Bostwick, D.J., Pacelli, A. and Lopez-Beltron, A. (1996) Molecular Biopsy of Prostatic Intraepithelial Neoplasia. Prostate, 29, 117-134. https://doi.org/10.1002/(SICI)1097-0045(199608)29:2<117::AID-PROS7>3.0.CO;2-C

[16] Montironi, R., Mazzucchelli, R., Algaba, F., et al. (2000) Morphological Identification of the Patterns of Prostatic Intraepithelial Neoplasia and Their Importance. Journal of Clinical Pathology, 53, 655-665. https://doi.org/10.1136/jcp.53.9.655

[17] Kim, N.W. and Hruszkewycz, A.M. (2001) Telomerase Activity Modulation in the Prevention of Prostatic Cancer. Urology, 57, 148-153. https://doi.org/10.1016/S0090-4295(00)00962-6

[18] Willman, J.H. and Holden, J.A. (2000) Immunohistochemical Staining for DNA Topoisomerase II-Alpha in Benign, Premalignant and Malignant Lesions of the Prostate. Prostate, 42, 280-286.

https://doi.org/10.1002/(SICI)1097-0045(20000301)42:4<280::AID-PROS5>3.0.CO; $\underline{2-\mathrm{P}}$

[19] Davidson, D., Bostwick, D.G., Qian, J., et al. (1995) Prostatic Intraepithelial Neoplasia Is a Risk Factor for Adenocarcinoma: Predictive Accuracy in Needle Biopsies. Journal of Urology, 154, 1295-1299. https://doi.org/10.1016/S0022-5347(01)66840-X

[20] Schoenfield, L., Jones, J.S., zippe, C.D., et al. (2007) The Incidence of High Grade Prostatic Intraepithelial Neoplasia and Atypical Glands Suspicious for Carcinoma on First Time Saturation Needle Biopsy, and the Subsequent Risk for Cancer. BJU International, 99, 770-774. https://doi.org/10.1111/j.1464-410X.2006.06728.x

[21] ArzozFabregas, M., Areal Calama, J., IbarzServio, L., et al. (2005) Isolated Intraepithelial Prostatic Neoplasia and Positive Prostate Adenocarcinoma Results at Re- 
peated Biopsy. Review of Our Series. Actas Urológicas Españolas, 29, 735-738. https://doi.org/10.1016/S0210-4806(05)73333-7

[22] De Nunzio, C., Trucchi, A., Miano, R., et al. (2009) The Number of Cores Positive for High Grade Prostatic Intraepithelial Neoplasia on Initial Biopsy Is Associated with Prostate Cancer on Second Biopsy. Journal of Urology, 181, 1069-1074. https://doi.org/10.1016/j.juro.2008.10.163

[23] Abdel-Khalek, M., El-Baz, M. and El-Houssieny, I. (2004) Predictors of Prostate Cancer on Extended Biopsy in Patients with High Grade Prostatic Intraepithelialneoplasia: A Multivariate Analysis Model. BJUI, 94, 528-533. https://doi.org/10.1111/j.1464-410X.2004.04996.x

[24] Bostwick, D.G., Liu, L., Brawer, M.K., et al. (2004) High Grade 23prostatic Intraepithelial Neoplasia. Reviews in Urology, 6, 171-179.

[25] Borboroglu, P.G., Sur, R.L., Roberts, J.L. and Amling, C.L. (2001) Repeat Biopsy Strategy in Patients with Atypical Small Acinar Proliferation on High Grade Prostatic Intraepithelial Neoplasia on Initial Prostate Needle Biopsy. Journal of Urology, 166, 866-870. https://doi.org/10.1016/S0022-5347(05)65853-3

[26] Kronz, J.D., Allan, C.H., Shaikh, A.A. and Epstein, J.I. (2001) Predicting Cancer Following a Diagnosis of High Grade Prostatic Intraepithelial Neoplasia on Needle Biopsy: Data on Men with More than One Follow Up Biopsy. The American Journal of Surgical Pathology, 25, 1079-1085. https://doi.org/10.1097/00000478-200108000-00014

[27] Rosser, C.J., Broberg, J., Case, D., et al. (1999) Detection of High Grade Prostatic Intraepithelial Neoplasia with the Five Region Technique. Urology, 54, 853-856. https://doi.org/10.1016/S0090-4295(99)00236-8

[28] Kamoi, K., Troncoso, P. and Babaian, R.J. (2000) Strategy for Repeat Biopsy in Patients with High Grade Prostatic Intraepithelial Neoplasia. Journal of Urology, 163, 819-823. https://doi.org/10.1016/S0022-5347(05)67811-1

[29] Epstein, J.I. and Herawi, M. (2006) Prostate Needle Biopsies Containing Prostatic Intraepithelial Neoplasia or Atypical Foci Suspicious for Carcinoma: Implications for Patient Care. Journal of Urology, 175, 820-834. https://doi.org/10.1016/S0022-5347(05)00337-X

[30] Ketch, D.W., Humphrey, P., Stahl, D.S. and Catalona, W.J. (1995) Morphometeric Analysis and Clinical Follow up of Isolated Prostatic Intraepithelial Neoplasia in Needle Biopsy of the Prostate. Journal of Urology, 154, 347-351.

https://doi.org/10.1016/S0022-5347(01)67044-7 